\title{
Simulation Study on Dynamic Reactive Power Compensation of Grid-Connected Wind Farms
}

\author{
Wang Xiao ming \\ College of Electrical and Information Engineering \\ Lanzhou University of Technology \\ Lanzhou, China \\ E-mail: majing111111@sina.com
}

\author{
Mu xing xing \\ College of Electrical and Information Engineering \\ Lanzhou University of Technology \\ Lanzhou, China \\ E-mail: 1571379480@qq.com
}

\begin{abstract}
With the Asynchronous wind generators as research object, this paper analyzes the problems of the voltage stability and the generation mechanism of the reactive power compensation during the wind farms connected operation. For paralleling capacitor bank has shown obvious defects, therefore this paper employs dynamic reactive power compensation to improve reactive characteristics of gridconnected wind farms. With the influences of different wind disturbances and grid faults on wind farms, wind farm model is set up and dynamic reactive power compensation system and wind speeds are built in the Matlab/Simulink software, The simulation result shows that they can provide reactive power compensation to ensure the voltage stability of the wind farms. But STATCOM needs less reactive compensation capacity to make sure the voltage and active power approaching steady state before the faults more quickly, Therefore STATCOM is more suitable for wind farms connected dynamic reactive power compensation.
\end{abstract}

Keywords-Wind farm, Reactive power compensation, STATCOM, Transient Stability

\section{INTRODUCTION}

The asynchronous wind turbines are mostly used in wind farms in China. The wind farms supply the active power to the grid when the wind turbines are connected to the grid, but at the same time, the reactive power is absorbed from grid, which would bring the reactive burden to the grid $^{[1-2]}$. Therefore, it is necessary to compensate the reactive power for grid-connected wind farm to eliminate the effects of voltage fluctuations which is caused by reactive power loss in grid and would lead to tripping operation of turbines as the terminal voltage drop. And the sufficient amount of reactive power compensation is needed to improve the safety and stable operation of the power grid in this case $\mathrm{e}^{[3-5]}$.

Currently, the method of connecting the asynchronous generator and capacitor banks in parallel permits is mostly used for wind farm reactive power compensation. However, with the rapid development of power electronics technology, this traditional reactive power compensation shows some obvious drawbacks and connecting the Flexible AC Transmission System (FACTS) to the wind farm to improve the operation characteristics become a necessity. And in this paper, the method with Static Var Compensator (SVC) and Static Synchronous Compensator (STATCOM) is proposed to compensate the reactive power in dynamic process to improve the operation condition of wind farm. We studied the impact of the wind farm connecting to the voltage of grid through simulating the dynamic model of wind farm containing the SVC and STATCOM structures in MATLAB/Simulink, and the simulation results analysis with these two structures is also compared.

\section{The Model Of ThE WIND TURBINES}

\section{A. Wind Speed Model}

In order to accurately describe the random and intermittent characteristics of wind speed, a wind speed model with four different kinds of wind speed is studied in this paper as following ${ }^{[6]}$.

$$
V_{\mathrm{W}}=V_{\mathrm{Wb}}+V_{\mathrm{Wg}}+V_{\mathrm{Wr}}+V_{\mathrm{Wn}}
$$

Where, $V_{\mathrm{Wb}}$ is the basic wind speed, $V_{\mathrm{Wg}}$ is gust wind speed, $V_{\mathrm{Wr}}$ is the gradient wind speed, and $V_{\mathrm{Wn}}$ is the random noise wind speed which would be described as the random noise of the wind component.

\section{B. The Model Of Asynchronous Wind Turbine}

The model which is used to described the asynchronous wind turbine need to reflect the static characteristics of the wind turbine. The asynchronous generator simplified equivalent circuit is shown in Fig.1.

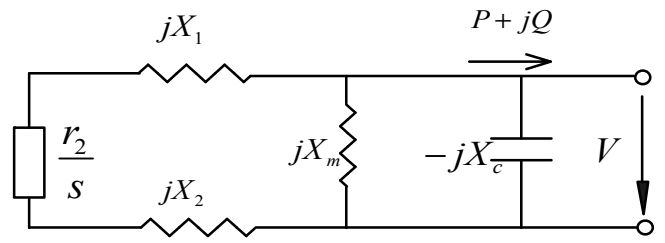

Fig.1 Simplified equivalent electrical circuit of induction machine

Where $X_{m}$ is the excitation reactance, $X_{1}$ is the stator leakage reactance, $X_{2}$ is the rotor leakage reactance, $X_{c}$ is the capacitor reactance, $r_{2}$ is the rotor resistance, $\mathrm{s}$ is the slip, and the stator resistance is ignored. With the circuit theory, the relationship between variables can be obtained by the Fig. 1 .

$$
P=\frac{V^{2}}{x^{2}+\left(r_{2} / s\right)^{2}} \cdot \frac{r_{2}}{s} \quad Q=-\left(\frac{V^{2}}{x_{p}}+\frac{P x}{r_{2} / s}\right)
$$


Where, $x=x_{1}+x_{2}, x_{p}=\frac{x_{c} \cdot x_{m}}{x_{c}-x_{m}}$.

It is assumed that the output active power of the wind generator as the fixed value in this study, and the relationship between power, voltage and slip by (3).

\section{THE MODELS OF DYNAMIC REACTIVE POWER COMPENSATION SYSTEM}

\section{A. Principles And Model Of The SVC}

The new power electronic components is introduced to the traditional static reactive power compensation devices by SVC, and which could adjust the reactive power more quick and smooth, maintain the voltage at the suitable value during the adjustment process. The SVC can be constituted by many forms, and the basic elements is Thyristor Controlled Reactor (TCR) and Thyristor Switched Capacitor (TSC). TCR smooth the control process. The output reactive power of SVC and the bus voltage connected to the SVC can be changed and adjusted by putting into and tripping the operation of TSC. The control system structure is shown as Fig.2.

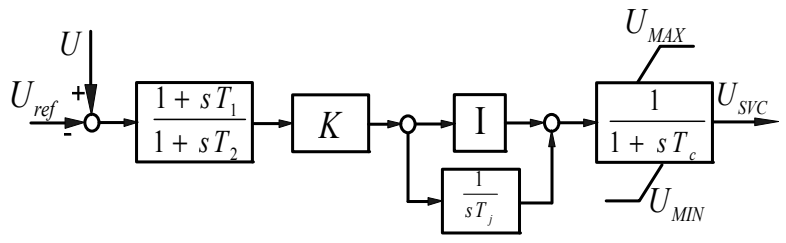

Fig.2 Structure of the SVC controller

The reactive power injected by SVC to the system is:

$Q_{S V C}=Q_{T S C}-Q_{T C R}=\left(\frac{1}{X_{T S C}}-\frac{2(\pi-\alpha)+\sin (2 \alpha)}{\pi X_{R}}\right) V^{2}$

Where,

$$
Q_{T C R}=\frac{V^{2}}{X_{T C R}}=\frac{2(\pi-\alpha)+\sin (2 \alpha)}{\pi X_{R}} V^{2}
$$

$Q_{T S C}=\omega C V^{2}=\frac{1}{X_{T S C}} V^{2}, \alpha$ is the firing angle, $\omega$ is the rated angular velocity of power, $X_{R}$ is the reactor impedance in TCR.

\section{B. Principles And Model Of The STATCOM}

STATCOM and SVC has the same basic function. However, as the STATCOM is the static var generator based on the full-controlled power electronic devices, in has the faster dynamic response, better stability, wider operating range and better characteristics of reactive power compensation than SVC device. The mathematical model of STATCOM can be expressed as:

$$
\frac{d}{d t}\left[\begin{array}{l}
i_{d} \\
i_{q} \\
V_{d c}
\end{array}\right]=\left[\begin{array}{ccc}
-\frac{R}{L} & \omega & \frac{m}{L} \cos \theta \\
-\omega & -\frac{R}{L} & \frac{m}{L} \sin \theta \\
-\frac{3 m}{2 C} \cos \theta & -\frac{3 m}{2 C} \sin \theta & 0
\end{array}\right] \cdot\left[\begin{array}{l}
i_{d} \\
i_{q} \\
V_{d c}
\end{array}\right]-\frac{1}{L}\left[\begin{array}{l}
V \\
0 \\
0
\end{array}\right]
$$

Where, $\omega$ is the rotational angular frequency of the q-r coordinate system, $m$ is the inverter modulation ratio, $V$ is the instantaneous voltage value of power system, $V_{d c}$ is the DC capacitor voltage, and $\theta$ is the phase difference between the output voltage and system voltage of STATCOM.

The reactive power injected by STATCOM to the system is:

$$
Q_{\text {STATCOM }}=\frac{V_{s}-V}{X_{e q}} V
$$

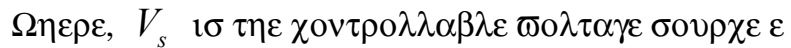

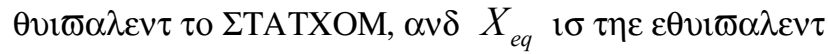
$1 \mu \pi \varepsilon \delta \alpha \nu \chi \varepsilon$. Fig.3.

The control system structure of STATCOM is shown in

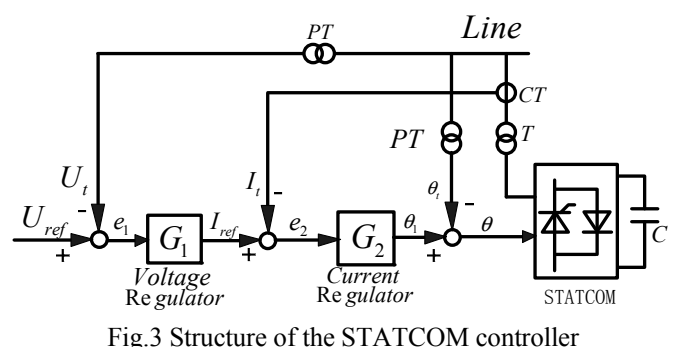

As it is shown in Fig.3, the transfer functions of the voltage regulator and current regulator are ${ }_{G_{1}}=\frac{K_{1}}{T_{1} S+1}$ and $G_{2}=\frac{K_{2}}{1+1 / T_{2} S} \cdot K_{1}$ and $K_{2}$ is respectively the proportionality coefficient of transfer functions, $T_{1}$ and $T_{2}$ are the time constant.

The output reactive current can be regulated by controlling the output voltage and the phase difference between the system synchronizing signals of the STATCOM. The controller uses the double-loop control mode, and the inner loop is the current loop and outer voltage loop. The output current of STATCOM can be regulated following the setting value with no static error by the PI controller in the current loop. The regulating loop of voltage can feedback the voltage of STATCOM access point, and comprise the voltage with the reference value, so as to achieve the proportional control. The outer ring of the output is given by the current loop.

\section{System DESCRIPTION AND SimULATION}

\section{A. System Description}

The simulation assumed that the wind farm connect to the infinite power system in this paper. As shown in Fig.4. 


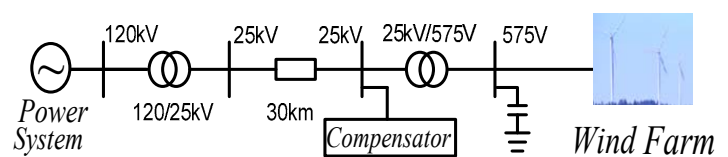

Fig.4 Sketch diagram of the studied power system

The wind farm is composed by 6 asynchronous turbines with $1.5 \mathrm{MW}$, the output voltage of wind farm is $575 \mathrm{~V}$, and it is connected with a transformer with $575 \mathrm{~V} / 25 \mathrm{KV}$ which could increase the voltage to $25 \mathrm{KV}$, and the power can be transported by $30 \mathrm{KM}$ transmission lines to the $120 \mathrm{KV}$ level booster station, then incorporated into infinity transmission system. The simulation model is built in Matlab/Simulation platform for simulation study.

\section{B. Wind Farm Simulation With Rated Wind Speed}

The rated wind speed is set to $9 \mathrm{~m} / \mathrm{s}$ in simulation, the connecting location of compensator STATCOM and SVC is shown in Figure 4. And following parts show the both simulation analysis.
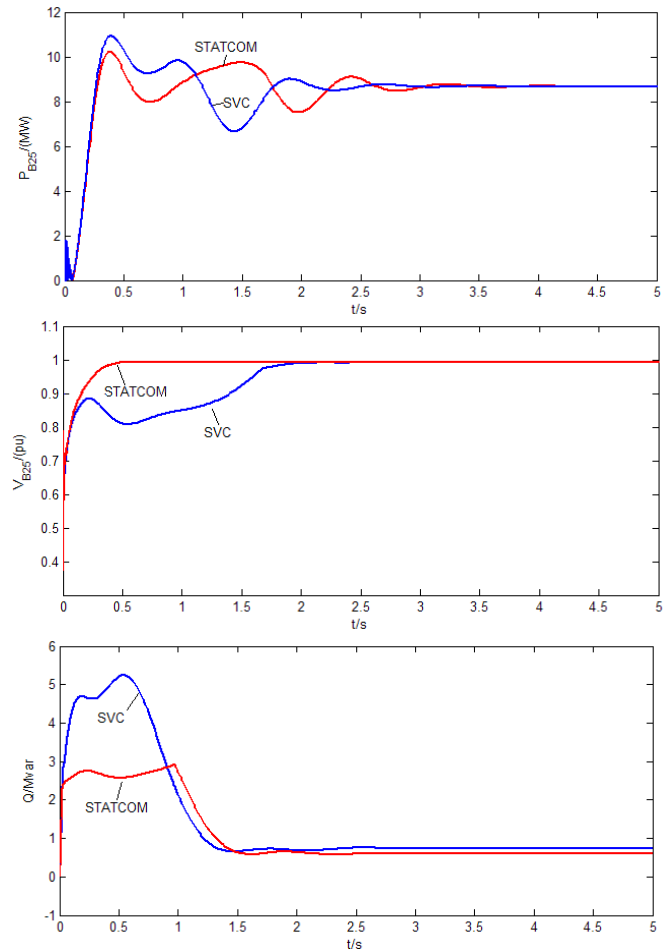

Fig. 5 The characteristics of the rated wind speed

It is observed from the simulation of the Fig.5 that the STATCOM is able to achieve good active and node voltage of the system, the compensation effect is more perfect than SVC, and the performance as following. First, the STATCOM can take advantage of security and stability improvements. Second, Reactive power of the STATCOM which provided to the system when the wind farm connects with power grid is less than using SVC, and we can find that the reactive power produced by SVC is 5 Mvar while STATCOM is only 2.5 Mvar.

\section{Simulation study in the failure of Wind farm}

The speeds of the wind ranging from $7 \mathrm{~m} / \mathrm{s}$ to $13 \mathrm{~m} / \mathrm{s}$ in $2 \mathrm{~s}$ to $6 \mathrm{~s}$. A remote fault will be simulated on systems at $10 \mathrm{~s}$, and the fault is cleared after $0.1 \mathrm{~s}$.
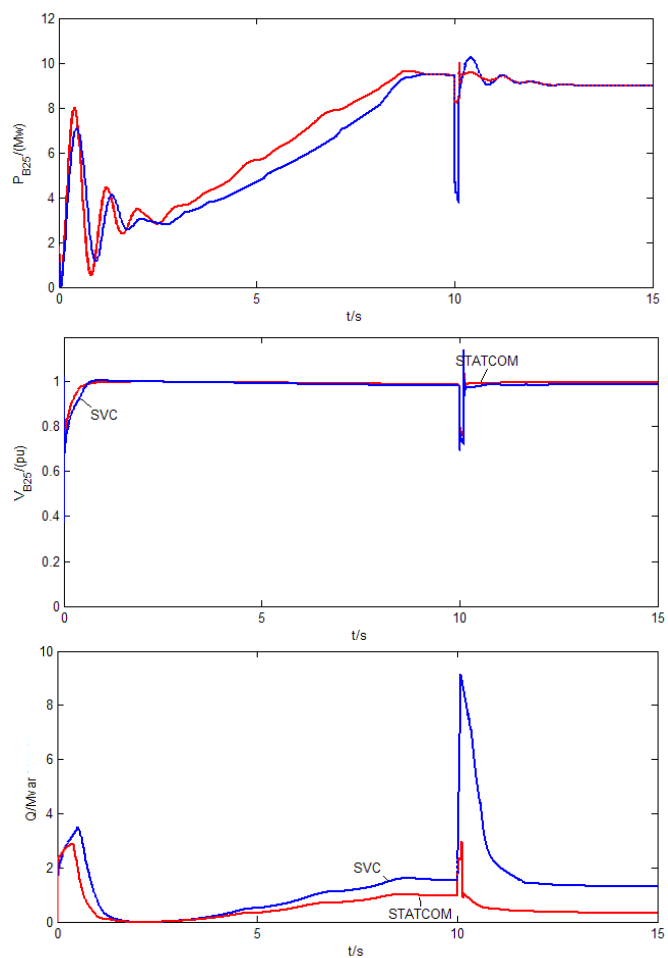

Fig.6 The characteristics of the fault condition

It is observed from the simulation of the Fig. 6 that the power system can return to a stable state when we adopt STATCOM to compensate more quickly after fault than SVC. It is found that SVC will need to provide the 9MW reactive compensation in order to keep the system stable, while STATCOM only needs 3MW.

\section{CONCLUSIONS}

In this paper, the model of asynchronous wind power and dynamic reactive power compensation system are established and simulated in the Matlab/Simulink software. There are two cases that the wind speed is maintained and the wind farm takes place ground fault. Based on the simulation results analyzed above two cases show that:

First, system voltage protection devices active and cut down the fault lines from the system, when the short circuit fault occurs without reactive power compensation device. And when increasing the reactive power compensation, the system enables regulate the voltage returns to the range allowed by the voltage protection device.

Second, the effect of STATCOM and SVC compensation has the differences, and the following twoconclusions can be drawn from the above simulation analysis:

a. The response speed of STATCOM has the faster and better stability control characteristics compared with SVC; and at the same stability limit, the capacity STATCOM 
needed is much smaller, nearly three times, than the SVC.

b. The control effect of STATCOM terms is better than $\mathrm{SVC}$, as the Voltage fluctuations occurs when the wind turbine connected to the grid.

\section{REFERENCES}

[1] Gu Wei, Li Xingyuan, and Wei Wei, "Simulation Comparison of the Improved Wind Power Dynamics by Means of SVC and STATCOM," J. Power System and Clean Energy, vol. 25, pp. 70-75, November, 2009.

[2] Yang Zhiyue, Li Fengting, "Simulation of Dynamic Reactive Power Compensation Scheme of Grid-Based Wind Farm," J. Electric Machines \& Control Application, vol. 38, pp. 34-38, November, 2011

[3] Jin Jing, Ai Qian, and Zhao Yan, "Reactive compensation principle and simulation of FACTS device in wind farm, " J. Electric Power Automation Equipment, vol. 27, pp. 58-61, August, 2007.
[4] Guo Lei, Wang Chunhua, and Gao Peisheng, "Analysis on Wind Turbine Tripping in Wind Farm of Chang ling Area," J. Jilin Electric Power, vol. 40, pp. 38-40, Feb. 2012.

[5] Wang Xiaolan, Wang Yaohui, "Voltage control at PCC of wind farm based on adjustment of reactive power of DFIG," J. Journal of Lanzhou University of Technology, vol. 36, pp. 84-89, Aug. 2010.

[6] Sun Jianfeng, "Research on Wind Farm Modeling and Simulating," D. 2004,Tsinghua University, Beijing, 2004.

[7] Zhang Ping, Liu Guopin, Zeng Xiangjun, Li Ling, Xia Yunfeng, and Yuan Chao, "Optimal allocation of reactive power source for wind farms," J. Power System Protection and Control, vol. 36, pp. 33-44, Oct. 16, 2008.

[8] Ren Puchun, Shi Wenhui, Xu Xiaoyan, and Zhao Haixiang, "A study of voltage stability improvement by static var compensators in the electric power system including wind farms," J. Electric Power, vol. 40, pp. 97-101, Nov.2007 